\title{
APRENDIZAGEM POR PROJETOS E OS CONTRATOS DIDÁTICOS
}

\author{
Prof. ${ }^{a}$ Dr. ${ }^{a}$ Marilda Aparecida BEHRENS \\ Prof. ${ }^{a}$ Ms. Eliane Mara Age JOSÉ
}

Resumo

O presente artigo apresenta os quatro grandes pilares de aprendizagem que sustentam a proposta da Declaração Mundial sobre Educação Superior no século XXI, que auxiliam no repensar sobre a ação docente e instigam a buscar novos caminhos para consolidar um ensino de qualidade que privilegie o aprender efetivo para os alunos.

Ressalta a Metodologia de Aprendizagem por Projetos, que propicia o acesso a maneiras diferenciadas de aprender, e especialmente, de aprender a aprender, partindo de problematizações que vinculem os temas a realidade circundante. Esta metodologia requer estudo e organização didática por parte do professor.

Ao enfocar a aprendizagem por projetos num paradigma emergente, defende a aliança entre pressupostos da visão sistêmica, da abordagem progressista e do ensino com pesquisa.

Ao abordar a concepção do Projeto pedagógico, contempla uma visão ampla, crítica e reflexiva, e pressupõe uma construção que venha a atender aos pressupostos do paradigma emergente, cujo foco central é o aprender a aprender. Para que este processo se realize, aponta os programas de aprendizagem e os contratos didáticos, como recursos pedagógicos significativos e relevantes na atuação docente numa sociedade do conhecimento.

Palavras-chave: Aprendizagem, metodologia, projetos, paradigma emergente, prática docente, programas de aprendizagem, contratos didáticos.

\section{Resumen}

El presente artículo presenta los cuatro grandes pilares del aprendizaje que sustentan la propuesta de la Declaración Mundial sobre la Educación Superior en el siglo XXI, que ayudan en la reflexión sobre la acción docente e instigam a buscar nuevos caminos para consolidar una enseñanza de calidad que privilegie el aprender efectivo para los alumnos.

El artículo resalta la Metodología del Aprendizaje através de Projectos, la cual propicia el acesso a maneras diferenciadas de aprender y especialmente, de "aprender a aprender", partiendo de problemáticas que vinculem los temas a la realidad circundante. Esta metodología requiere estudio y organización didáctica por parte del profesor.

Al enfocar el aprendizaje através de projectos en un paradigma emergente, el artículo defiende la alianza entre los presupuestos de una visión sistemática de abordaje progresista y la enseñanza como investigación.

Al abordar la concepción del projeto pedagógico, el artículo contempla una visión amplia, crítica y reflexiva y presupone una construcción que atienda los presupuestos del paradigma emergente, cuyo foco central es "aprender a aprender".

Para que este proceso se realize, son indicados los programas de aprendizaje y los contratos didácticos como recursos pedagógicos significativos y relevantes en la actuación docente en una sociedad de conocimiento.

Palabras llave: aprendizaje, metodología, projectos, paradigma emergente, práctica docente, programas de aprendizaje, contratos didácticos.

* Mestre e Doutora em Educação. Professora de Didática na Pedagogia e de Paradigmas Contemporâneos no Mestrado em Educação da PUCPR.

** Mestre em Educação. Professora de Didática e Prática de Ensino da PUCPR. 


\section{Introdução}

A concepção de uma prática pedagógica que contemple uma visão ampla, crítica e reflexiva, pressupõe uma construção que atenda aos pressupostos do paradigma emergente, que tem a produção do conhecimento como eixo fundamental e cujo foco central é a aprendizagem. A proposição apresentada no relatório Internacional da UNESCO para Educação do Século XXI, apresentada por DELORS (1998), propõe quatro grandes pilares para aprendizagem ao longo da vida: aprender a conhecer, aprender a fazer, aprender a ser e aprender a conviver. Com a visão de que essas aprendizagens não se apresentam separadamente, mas se interconectam num todo harmonioso e complexo, destacam-se para fins didáticos suas proposições.

O primeiro pilar relacionado aponta para o aprender a conhecer focado no aprender a aprender, aprender a raciocinar, a investigar e aprender a pensar. O segundo pilar destaca o aprender a fazer com intuito de desenvolver aptidões, habilidades e competências no sentido de atuar, de resolver conflitos, de saber comunicar-se, para enfrentar desafios e ter iniciativa própria para resolver problemas.

O terceiro pilar apontado é o aprender a conviver, que propõe a dimensão de viver em comunidade, trabalhar harmoniosamente com seus pares, aprender a trabalhar em parcerias ou em grupo, ter equilíbrio e atitude ética para compreender o outro como parceiro, administrar conflitos, buscando harmonia e solidariedade, ter prazer em compartilhar o sucesso coletivo, ser responsável para participar em projetos conjuntos que demandem cooperação e colaboração.

O quarto pilar apresentado no relatório envolve o aprender a ser no sentido de desenvolver a sensibilidade, valorizar as inteligências múltiplas, ser solidário e amoroso, ser ético e político na vivência da cidadania plena, ter pensamento crítico e reflexivo que levem a atitudes de autonomia visando a uma melhor qualidade de vida para si mesmo e seus semelhantes.

Esses pilares de aprendizagem sustentam a proposta da Declaração Mundial sobre Educação Superior no Século XXI: Visão e Ação, elaborada em relatório da UNESCO, em Paris (1997), pelos educadores de todas as nacionalidades. Neste contexto, cabe à escola, em especial, às universidades, a responsabilidade social de oportunizar ações e intervenções que levem a comunidade acadêmica a refletir, analisar e buscar construir projetos pedagógicos que venham a atender à formação do homem com uma visão de mundo mais igualitária, mais justa e mais solidária. Assim, a Sociedade do Conhecimento, que vem conformando as últimas décadas, demanda repensar a educação em sua totalidade, e, em especial, a prática pedagógica dos professores universitários, contemplando as seguintes visões para o século XXI: 
- Visão de totalidade - considera-se que a prática pedagógica deve superar a visão fragmentada, retomando as partes num todo significativo.

- Visão de rede, de teia, de conexão - considera-se que os fenômenos estão interconectados, havendo uma relação direta de interdependência entre os seres humanos.

- Visão de sistemas integrados - considera-se que todos os seres humanos devem ter acesso ao mundo globalizado, aumentando assim as oportunidades para construir uma sociedade mais justa, igualitária e integrada.

- Visão de relatividade e movimento - considera-se que é essencial ter uma percepção de que os conhecimentos são relativos, não existindo uma verdade absoluta, e que esses conhecimentos estão em constante movimento, qualquer esforço em solidificar a verdade poderá ser redimensionado em momentos subseqüentes por novas descobertas.

- Visão de cidadania e ética - considera-se que a formação dos seres humanos deve estar alicerçada na construção da cidadania com uma postura ética, em que exista o respeito aos valores pessoais e sociais, espírito de solidariedade, justiça e paz. ( BEHRENS e ALCÂNTARA, CDROM, 2001).

A ampliação das visões em busca de articulações e de interconexões na aprendizagem vem exigindo um repensar sobre a ação docente que instigue a busca de novos caminhos para consolidar um ensino de qualidade que privilegie 0 aprender efetivo para os alunos.

\section{Metodologia de aprendizagem por projetos}

A opção por um ensino baseado em projetos proporciona a possibilidade de uma aprendizagem pluralista e permite articulações diferenciadas de cada aluno envolvido no processo. Ao alicerçar projetos, o professor pode optar por um ensino com pesquisa, com uma abordagem de discussão coletiva crítica e reflexiva que oportunize aos alunos a convivência com a diversidade de opiniões, convertendo as atividades metodológicas em situações de aprendizagem ricas e significativas. Esse procedimento metodológico propicia o acesso a maneiras diferenciadas de aprender, e, especialmente, de aprender a aprender.

A metodologia de ensino por projeto foi proposta inicialmente por Dewey (1968), por volta dos anos trinta, na abordagem da Escola Nova. Segundo os autores LEITE, MALPIQUE, SANTOS (1990), para Dewey: 
A brusca inibição dum impulso transforma-o em desejo. Todavia, é preciso insistir nisso nem o desejo realiza um projecto. O projecto supõe a visão de um fim. Implica uma previsão de conseqüências que resultariam da acção que se introduz no impulso inicial. A previsão das conseqüência implica, ela mesma, o jogo da inteligência. Esta exige, em primeiro lugar, a observação objectiva das condições e das circunstâncias. Porque o impulso e desejo produzem conseqüências, não por elas mas pela sua interaç̧ão e cooperação com as condições envolventes.( In: Leite, Malpique, Santos, p.15 )

Acrescenta-se que não basta a observação, mas a significação que se atribui para as atividades que serão desenvolvidas no projeto. O professor precisa levar em consideração as condições a serem oferecidas aos alunos. Enfatizase que o ponto inicial do projeto precisa considerar o conhecimento que já foi produzido sobre a temática ou o problema proposto.

O professor e o aluno, numa ação conjunta, precisam aprender a pesquisar e a desenvolver o espírito de investigação constante. $\mathrm{O}$ docente por ser mais experiente tem a responsabilidade de desencadear este processo e buscar fornecer as primeiras pistas sobre os conhecimentos disponíveis nas bibliotecas, nas redes informatizadas, nos livros, nos CDs, nos periódicos ou nas revistas especializadas.

Nesse processo de pesquisa e aprendizagem, recomenda-se que o professor crie possibilidades para investigar recursos variados que levem o aluno a aprender a aprender, como e onde buscar a informação, como elaborar e produzir conhecimento próprio. Partindo de pontos norteadores que subsidiem o processo de investigação, o docente pode fornecer alguns itens ou referenciais bibliográficos que possam auxiliar o encaminhamento dos alunos para a pesquisa, deixando claro que eles podem e devem buscar com autonomia outras fontes de informações.

Na metodologia de ensino por projetos os estudantes terão que pesquisar, discutir, elaborar e, especialmente, discernir entre o que é ou não relevante para construir conhecimento durante o processo. DEWEY (1968) acrescenta:

O verdadeiro método pedagógico consiste primeiro em tornarmonos inteligentemente atentos às aptidões, às necessidades, às experiências vivenciadas pelo educandos e, em segundo lugar, em desenvolver estas sugestões de base de tal forma que elas se transformem num plano ou num projecto que, por sua vez, se organize num todo assumido pelo grupo. Por outras palavras, o plano é um empreendimento cooperativo e não ditatorial: a sugestão do professor não deve evocar a idéia de um molde para fundir objectos duros, pesados e inertes, mas a de um ponto de dilatação susceptível de se transformar num todo ordenado pelas contribuições de todos aqueles que se empenham em comum na mesma experiência educativa. É graças a uma troca 
recíproca do professor e dos alunos que se faz este crescimento, o professor recebe mas não tem medo de dar. O ponto essencial a reter é que o projecto cresce e toma forma graças a um processo de inteligência socializada. ( In: LEITE, MALPIQUE, SANTOS, 1993, p. 23 )

A metodologia proposta inicialmente por DEWEY continua sendo pertinente e válida ao longo dos anos. Sua proposta foi se desenvolvendo e se reinventando, se reconstruindo e, hoje, aparece reescrita por outros autores, que buscam aliar a metodologia de projetos a uma abordagem progressista, crítica e reflexiva. Com o advento da Sociedade do Conhecimento e o foco na aprendizagem proposta pela UNESCO, acredita-se na pertinência de denominar a metodologia de "ensino por projetos" para "aprendizagem por projeto".

Em realidade, a abordagem progressista, proposta com ênfase a partir dos anos oitenta, por FREIRE (1997) e GIROUX (1997), entre outros, norteia com seus pressupostos a metodologia de aprendizagem por projeto e, para tanto, contempla a discussão crítica e dialógica sobre as informações pesquisadas para produzir conhecimento relevante e significativo. Ao propor atitudes dialógicas o professor propicia a opção por um posicionamento dialético que implica um movimento constante de renovação; desta maneira, pode passar a oferecer conexão entre pesquisa, ação, reflexão e a produção do conhecimento.

A metodologia de aprendizagem por projetos implica partir de problematizações que vinculem os temas à realidade circundante. $O$ cuidado de considerar o contexto tem se apresentado como uma opção significativa de ensinar e, especialmente, de aprender a aprender em situações reais. Para HERNÁNDEZ e outros (2000, p.134 e 135), os projetos de trabalho:

São respostas à necessidade de realizar uma organização globalizada e atualizada dos conhecimentos e das informações trabalhadas na escola. $\mathrm{O}$ sentido da globalização não consiste em um somatório de informações disciplinares, mas em encontrar o nexo, a estrutura cognoscitiva, o problema central, que vincula os conhecimentos e possibilita aprendizagem. Os projetos fundamentam sua concepção teórica em:

a) Um sentido da aprendizagem que se pretende construir de modo significativo para os alunos.

b) Sua articulação a partir de atitude favorável para o conhecimento por parte dos meninos e das meninas.

c) A previsão, por parte dos professores, da estrutura lógica e seqüencial dos conhecimentos que pareça mais adequada para facilitar sua assimilação.

d) A funcionalidade do que se aprende como um elemento importante dos conhecimentos que os alunos irão aprender. 
Numa fase inicial do projeto o aluno acostumado a ser instruído mecanicamente numa abordagem tradicional e de obedecer às ordens do professor, apresenta-se confuso e angustiado. O professor precisa ter paciência histórica para entender o aluno nesse processo de mudança metodológica. Para tanto, deve ter o cuidado de discutir o projeto com os alunos, esclarecer as fases propostas e estimulá-los a participarem do processo. Afinal, o estudante está aprendendo projetar e precisa superar as certezas e as respostas prontas e inquestionáveis que o condicionaram na abordagem conservadora. $\mathrm{O}$ crescimento dos alunos aparece quando relaxam a defensibilidade e entendem que dependerão uns dos outros para aprenderem num processo emancipador com autonomia e espírito reflexivo. A contribuição de HERNANDÉZ (2000, p.182) valida essa reflexão quando comenta:

O que aparece como defensivo é que a aprendizagem e o ensino são realizados por meio de uma trajetória que nunca é fixa, mas que serve como fio condutor para atuação do docente em relação aos alunos. Tê-lo presente serve de auxílio, de ponto de referência, sobre o que significa um projeto em relação ao diálogo e à negociação com os alunos, à atitude interpretativa do docente, aos critérios para a seleção de temas, à importância do trabalho com diferentes fontes de informação, à relevância da avaliação como atitude de reconstrução e transferência do apreendido, etc.

O professor precisa declarar seu envolvimento e credibilidade na competência e qualidade dos alunos e, especialmente, na credibilidade que todos os alunos podem e são capazes de realizar as atividades propostas. Segundo SCHÖN (2000, p. 79), "O paradoxo de aprender uma competência realmente nova é este: um estudante não pode inicialmente entender o que precisa aprender; ele pode aprendê-lo somente educando a si mesmo e só pode educar-se começando a fazer o que ainda não entende". Nessa perspectiva, o desafio do envolvimento em novas aprendizagens se dá em duas dimensões, tanto na individual como na coletiva.

Os procedimentos metodológicos são diferenciados, mas os alunos assumem compromissos próprios com o grupo e passam a produzir aprendizagem para o projeto que estão desenvolvendo e não para um trabalho acadêmico pedido pelo professor. $\mathrm{O}$ aluno passa a educar-se e a cumprir com responsabilidade compromissos pessoais de aprendizagem firmados com 0 grupo e com o professor. Num primeiro momento, as atitudes individualistas e conservadoras são pautas de discussões no grupo e merecem ser atendidas e articuladas pelo professor que tem o papel de mediador do novo processo. O docente pode não estar habituado a propor situações que oportunizem o dialogo com os alunos e, por conseqüência, não está acostumado a possibilitar questionamentos, sentindo dificuldade para abandonar a abordagem tradicional, conservadora e autoritária de comandar seus alunos. 
No entanto, torna-se urgente e necessária uma ação didática que viabilize a produção do conhecimento. Para tanto, há necessidade de reconstruir a prática pedagógica exigindo do professor uma nova aprendizagem nas atividades propostas pela metodologia, nas atitudes e na condução do processo metodológico. Cabe a análise de que o docente acostumado com verdades e certezas absolutas passa a questionar sua própria docência e passa a ter dúvidas acerca da sua competência para orientar os educandos no processo.

A proposição da aprendizagem por projetos pode ser organizada de maneiras diferenciadas, mas em geral iniciam com uma problematização. Esse processo pode ser desencadeado com a proposição de problema construído junto com os alunos ou trazidos pelo professor ou ainda por várias perguntas de pesquisa. O início do processo metodológico que contemple a problematização implica propor problemas mais gerais ou mais específicos focados em uma única temática ou que demandem a interconexão de vánios temas de estudo e aprendizagem. Não há certezas absolutas, nem respostas predeterminadas, nem respostas prescritivas ou indicadas por um único autor, portanto, não se restringe à abordagem de consulta e ao uso de um único livro texto. Mas implica a produção do conhecimento individual e coletivo do aluno advinda do envolvimento na investigação e na pesquisa, partindo do problema proposto no projeto. Para HERNÁNDEZ (1998, p.61),

A função do projeto é favorecer a criação de estratégias de organização dos conhecimentos escolares em relação a:1) o tratamento da informação e 2) a relação entre os diferentes conteúdos em torno de problemas ou hipóteses que facilitem aos alunos a construção de conhecimentos, a transformação da informação procedente dos diferentes saberes disciplinares em conhecimento próprio.

Essa metodologia requer um estudo e planejamento prévio do docente, investigando qual o problema que poderá absorver a proposta de conhecimentos que precisam ser envolvidos naquela etapa de aprendizagem dos alunos. O ensino centrado em problemas, bem como a metodologia de projetos, terá que ser "criteriosamente estruturado, pelo docente, com vistas a que os estudantes possam tirar proveito de suas experiências. Neste caso, caberá ao docente/orientador do processo-e creio que os estudantes- selecionar problemas que, pelo seu valor exemplar, tenham um significado científico e/ou metodológico para os discentes" (CORREIA, P; MADUREIRA,C; DOMINGUES, A, IN: LEITE, MALPIQUE, SANTOS, 1993, p.26). A exigência e o rigor não podem ser confundidos com engessamento ou com um método rígido a ser seguido, mas implica envolver os docentes e os discentes na investigação de um maior domínio sobre os assuntos, matérias e informações. Para tanto, o docente precisa acessar um amplo espectro de conhecimento sobre a problemática proposta e estar disposto a dialogar e construir conhecimento com os alunos. 
O homem vivendo em sociedade está sempre envolvido com problematizações que requerem seu discernimento, atuação, rapidez de raciocínio e autonomia para tomar decisões. Com essa perspectiva CORREIA; MADUREIRA; DOMINGUES (In: LEITE, MALPIQUE, SANTOS, 1993) acrescenta:

É neste contexto que deve ser inserido o estudo por projecto centrado em problemas, pois para além deste método contribuir para o acréscimo de informações ao nível cognitivo, contribui também, e em larga medida, para auxiliar o aluno a (re)descobrir, quer aquilo que tem dentro de si, quer aquilo que o rodeia. Assim, o estudo por projecto centrados em problemas surge uma forma de levar o estudante a agir sobre a informação, integrá-la nos seus conhecimentos anteriores, reestruturando-a, levando-0, também, a pensar criticamente, trabalhar em equipe,resolver problemas, emitir juízos de valor, comunicar, questionar e questionar-se de acordo com suas experiências, motivações e necessidades. (p.30)

\subsection{A aprendizagem por projetos num paradigma emergente}

O desencadeamento da aprendizagem por projetos precisa oferecer como procedimentos metodológicos ações que provoquem a produção de conhecimento individual e coletivo. A superação de uma visão conservadora assentada em aulas tradicionais restritas à cópia e à memorização exige a reconstrução uma prática pedagógica que contemple um paradigma emergente, portanto crítico, reflexivo e transformador. Realizando pesquisas sobre a prática pedagógica junto a professores universitários, BEHRENS $(1998,2000)$ defende, para o Paradigma Emergente, uma conexão entre os pressupostos da visão sistêmica, da abordagem progressista e do ensino com pesquisa. Aponta que nessa aliança também deverá ser incluída como recurso auxiliar para aprendizagem a tecnologia inovadora, especialmente os recursos informatizados. Portanto, cabe a contribuição de ALCANTARA e BEHRENS (2001) quando esclarecem que a prática pedagógica precisa orquestrar uma aliança entre:

- Abordagem Progressista: Relação dialógica, crítica, reflexiva, com ações articuladas, trabalho coletivo e busca da transformação da realidade.

- Abordagem do Ensino com Pesquisa: Parceria dos alunos e professor na busca da produção do conhecimento e na superação da cópia e da reprodução.

- Abordagem Holística ou Sistêmica: Reaproximação das partes na busca da visão do todo, de um sistema integrado e interconectado. 
( ALCÂNTARA, P. e BEHRENS, M. A, CRROM, 2001).

\subsection{Fases da aprendizagem por projetos}

A partir desta teia de abordagens metodológicas, BEHRENS (2000, p.108) apresenta como sugestão a ser ampliada ou adaptada as seguintes fases a serem desenvolvidas para buscar uma aprendizagem significativa:

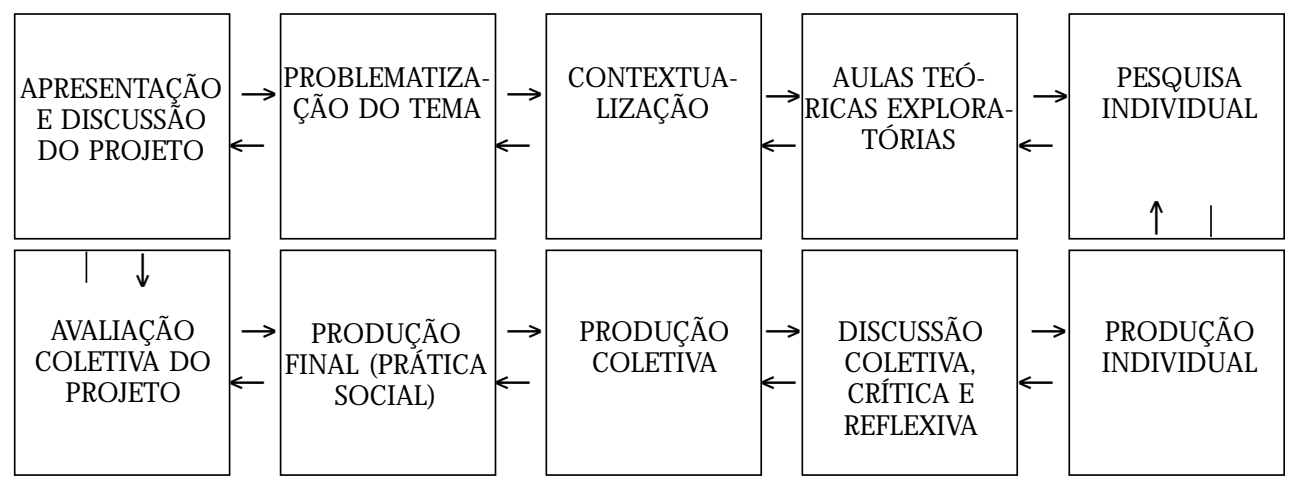

Fonte: Behrens, M. Projetos de aprendizagem colaborativa num paradigma emergente. IN: BEHRENS,M; MORAN, J. M; MASETTO, M. Novas tecnologias e mediação pedagógica. Campinas: Papirus,2000, p 108.

A discussão do projeto torna-se significativa, nesta fase inicial, pois o professor apresenta aos alunos uma minuta de proposta, que elaborou e submetem à apreciação dos alunos, denominada por PERRENOUD (1999) como contrato didático. $\mathrm{O}$ docente precisa ter clareza que há necessidade de apreciar e reconstruir, se necessário e pertinente, a proposta com os alunos. A aceitação das opiniões dos alunos numa relação dialógica é significativa e relevante para o sucesso da produção do conhecimento. Os alunos que ainda não estão habituados a participar de um processo participativo encontram algumas dificuldades de se manifestar com receio de sofrerem repressões ou constrangimento na sala de aula. O docente precisa deixar claro, o processo crítico, participativo e dialógico que irá caracterizar o projeto desde a fase inicial.

A aprendizagem por projetos pode ser iniciada pela problematização, que demanda um preparo do professor para elaborar questões pertinentes e significativas sobre a temática proposta. A problematização precisa ser colocada como provocação para estimular os alunos a se envolver no projeto.

As fases propostas no projeto incluem também a contextualização para localizar historicamente a temática, as aulas expositivas dialogadas, nas quais o professor apresenta os temas, os conhecimento, conteúdos, as informações envolvidos na temática, subdivididos em itens e subitens orientadores a serem pesquisados. No desencadeamento do processo, o pro- 
fessor instiga os alunos para realizarem a pesquisa individual e trazerem para sala de aula o material investigado com a finalidade de alicerçar a produção individual do aluno, num texto próprio sobre a problemática ou outro procedimento que o docente julgar oportuno. A seguir, o docente pode propor uma discussão crítica e reflexiva consubstanciada na pesquisa e produção individual, e a partir deste ponto os alunos podem produzir conhecimento coletivamente. $O$ professor e os alunos devem discutir a possibilidade de aplicação da produção numa atividade final, que pode consolidar-se desde um texto a ser disponibilizado na sala para todos ou na internet até uma campanha de conscientização da comunidade na problemática que está sendo investigada.

Na avaliação da aprendizagem será proposta, de maneira contínua, a partir da discussão do processo e dos critérios acordados no contrato. Os alunos precisam manifestar-se sobre as atividades propostas com o intuito de melhorá-las ou mantê-las. As avaliações da aprendizagem devem incluir as atividades individuais e coletivas, bem como o valor atribuído a cada fase do projeto. $\mathrm{O}$ aluno precisa sentir-se seguro de que será avaliado com transparência, e estar consciente de que se não corresponder aos critérios estabelecidos e acordados pelo próprio grupo, não será aprovado. Não se trata de favorecer a ociosidade e nem ser benevolente com a falta de compromisso por parte do aluno ou de algum grupo. Para isso, durante o processo, o professor deverá dialogar e discutir com os alunos seu envolvimento, desenvolvimento e qualidade nas atividades propostas. Este processo se estende na avaliação contínua do projeto. As manifestações dos alunos são extremamente relevantes para a reestruturação ou manutenção do projeto proposto.

As fases sugeridas não se esgotam, nem pretendem ser um engessamento na criatividade do docente, mas servem como ações didáticas que deverão ser consideradas no processo. Acredita-se que a sugestão possa ser estendida, pois o docente sabe quais as aptidões, habilidades e competências deverão ser contempladas e quais as necessidades de sua disciplina ou programa de aprendizagem. Os docentes, ao optarem por propor aprendizagem por projetos, devem considerar nas suas ações didáticas:

Crítica-contempla atividades que permitam uma relação dialógica, crítica e reflexiva entre professores e alunos.

Argumentação-possibilita a defesa de suas idéias elaboradas e produzidas com fundamentação.

Pesquisa-propicia uma investigação dos referenciais teórico-práticos disponíveis em recursos bibliográficos e eletrônicos que permitem subsidiar a produção de conhecimento próprio.

Participação instiga o envolvimento efetivo nas atividades propostas, estimulando a responsabilidade entre pares. 
Análise-busca desenvolver atitudes críticas e reflexivas frente a elaboração e produção do conhecimento.

Trabalho individual e coletivo-contempla a elaboração responsável nas atividades individuais para subsidiar com propriedade as produções coletivas. Criação-permite e estimula a proposição de problematizações que levem a autonomia e a iniciativa instigando processos criativos.( ALCÂNTARA, P. e BEHRENS, M.. CDROM, 2001).

\subsection{A prática docente e o projeto pedagógico}

A proposição de aprendizagem por projetos que contemplem os pressupostos do paradigma emergente depende de um processo de mudança na postura do professor e do aluno. O movimento de transformação implica um processo maior que precisa ser desencadeado pelas Instituições de Ensino em todos os níveis. Neste momento histórico, por uma determinação legal prescrita na Lei no 9394/96, há necessidade de os gestores construírem junto com os docentes projetos pedagógicos com intuito de alicerçar possibilidades para desenvolver uma prática pedagógica relevante e significativa.

A concepção do Projeto Pedagógico que contemple uma visão ampla, crítica e reflexiva, pressupõe uma construção que atenda aos pressupostos do paradigma emergente, cujo foco central é o "aprender a aprender". O projeto pedagógico demanda processos de envolvimento, reflexão, discussão e elaboração junto com os professores e gestores. As discussões precisam focar-se, em especial, na visão de homem e de mundo oferecida naquela instituição. Este posicionamento institucional está intimamente ligado `a visão de educação e de prática pedagógica que irá alicerçar a proposição dos Cursos de Graduação.

Os professores envolvidos no projeto pedagógico, e na educação em geral, precisam instigar seus alunos a realizarem atividades que demandem: "Interdependência; Participação efetiva; Interdisciplinaridade; Proposição de produção do conhecimento; Elaboração Própria; Autonomia e iniciativa; Análise crítica e reflexiva. (ALCANTARA, P. e BEHRENS, M, CDROM, 2001).

A partir destes pressupostos, cabe rever a organização didática de todo e qualquer Curso.

\section{Os programas de aprendizagem e os contratos didáticos}

A prática pedagógica dos professores que atuam nas Instituições de Educação Superior precisa ser construída a partir dos pressupostos apontados pelo paradigma emergente. O posicionamento do professor para reestruturar sua ação docente precisa ser acompanhado de organização das atividades 
didáticas que serão oferecidas aos alunos. Alguns docentes conservadores terão que reorganizar, completamente, sua maneira de agir e sua visão do papel do aluno no processo educativo.

Recomenda-se que a renovação da ação docente venha acompanhada da elaboração de programas de aprendizagem e dos contratos didáticos.

\subsection{Os programas de aprendizagem}

A mudança do foco do ensino para aprendizagem permite refletir e sugerir que as disciplinas passem a ser denominadas programas de aprendizagem $^{3}$. A denominação disciplinas dentro dos currículos advém do pensamento newtoniano-cartesiano que tem como ponto central a fragmentação, a linearidade e o reducionismo. Este paradigma conservador tende a ser superado neste século. A sociedade do conhecimento acompanha um paradigma da ciência que propõe a recuperação da visão de totalidade, buscando a visão de interconexão e de inter-relacionamento. Não se trata de mudar a denominação de disciplinas, mas de criar um novo processo pedagógico. A partir desta concepção, passa-se a analisar e discutir as disciplinas ou os programas de aprendizagem a serem elaborados, de preferência, reunindo os professores por períodos para que possam conhecer todos os programas propostos no semestre e, posteriormente, dos cursos em geral.

A proposição de cada professor, ao elaborar seu programa de aprendizagem e discuti-lo com seus pares, apresenta vantagens significativas, pois além de receber um retorno de seus colegas, passa a ter entendimento da oferta dos programas de aprendizagem em seu conjunto. Esse cuidado metodológico na elaboração dos programas de aprendizagem permite ao docente uma visão de totalidade, de interconexão e da necessária articulação entre os vários períodos que compõem um curso.

Num primeiro momento, a instituição precisa criar a oportunidade para os professores tomarem ciência da proposta curricular elaborada ou a ser construída. Nessa ocasião, os docentes poderão discutir, reelaborar, manter ou alinhar seus Programas de Aprendizagem de acordo com a proposta curricular, com o perfil do profissional desejado, com as recomendações internas da instituição e das Diretrizes Curriculares proposta pelo Ministério de Educação. Cabe esclarecer que neste momento histórico, mesmo dependendo de aprovação no Conselho Nacional de Educação, as Diretrizes Curriculares estão sendo atendidas pelos vários cursos de Graduação.

O projeto pedagógico de um Curso depende inteiramente da formação continuada de seus docentes e da oportunidade de envolvimento e participação proposta pelos seus gestores das Instituições de Ensino Superior. Cabe salientar que, se os professores não se envolverem na proposta pedagógica, nada vai alterar em sala de aula. 
Neste contexto, convém lembrar que o processo de construção do projeto pedagógico depende do envolvimento e participação dos professores, em especial, a busca do conhecimento de todos os programas que compõem o Curso e, quem sabe, da criação de possibilidades de atuação conjunta de vários programas de aprendizagem na articulação de projetos conjuntos.

Outro fator relevante a ser apontado é a possibilidade de criar espaço para que os professores possam se encontrar e discutir o Curso na sua totalidade. Os programas de aprendizagem e a prática pedagógica a ser ofertada aos alunos. Os horários de permanência devem ser distribuídos de maneira a contemplar tempo para reuniões, para investigação e pesquisa por parte do professor em função da montagem e elaboração dos programas de aprendizagem, incluindo tempo para atender os alunos, tempo para leitura, orientação e registro das avaliações contínuas e processuais.

Ao elaborar os programas de aprendizagem, os professores devem levar em consideração alguns itens que são indispensáveis para sua construção. Portanto, cada programa de aprendizagem pode ser apresentado de maneira enxuta, contendo a ementa, as competências, habilidades ou aptidões ${ }^{4}$, os temas centrais e seus desdobramentos, a metodologia a ser proposta, a proposição da avaliação e a bibliografia. O professor ao propor os programas de aprendizagem deve prever seu desdobramento num contrato didático de trabalho ou plano de trabalho.

A ênfase na aprendizagem como a preocupação essencial do processo educativo leva a refletir: Mas se os professores estão ensinando os alunos não estão aprendendo? Ao se dialogar com os docentes eles acreditam que a resposta seria positiva. No entanto, os alunos apresentam argumentos como:

"O professor passa os conteúdos com intuito dos alunos decorem e depois realizarem as provas"

"Quando o professor está ensinando parece que está dando aula para ele mesmo, utiliza um grande esforço para se fazer entender, mas não pergunta se os alunos estão entendendo...para que estão estudando tal conteúdo, com que finalidade ou onde irão aplicá-lo"

"Como o professor vai ensinando passo a passo os fragmentos dos conteúdos, os alunos demoram para entender do que se trata aquela temática. Às vezes, levam mais de quatro ou cinco aulas para começar a perceber alguma articulação entre as partes".

A partir dos depoimentos dos alunos, pode-se perceber que os professores trabalham e são responsáveis. Mas não têm percebido que os tempos mudaram e que a repetição e a reprodução do conhecimento não satisfazem os alunos e não atendem às exigências da sociedade do conhecimento. Parece que os estudantes se alertaram antes que os docentes sobre o que terão que enfrentar como profissionais. 
O momento atual evidencia a ocorrência contínua de profundas transformações sociais, o que implica mudanças em todos os aspectos na vida, e cabe enfatizar que as instituições, de maneira geral, precisam reestruturar-se, tendo em vista tal realidade. Também, ou principalmente, as escolas precisam mudar. Os tempos atuais exigem uma cultura ampla e criativa, que permeie toda a ação na sociedade, ramificando-se por todas as instituições.

O progresso vertiginoso em determinadas áreas da atividade humana não se vem fazendo acompanhar de mudanças qualitativas nas instituições educacionais, que devem educar, para construir uma sociedade mais justa e igualitária. Os desafios são acompanhados, muitas vezes, de preocupante degradação, em todos os âmbitos sociais, conseqüência esta do crescente desemprego e da exclusão social. Segundo VEIGA (2000), é nesse contexto que a educação deve ser pensada.

Busca-se uma educação que estimule os jovens e adultos a buscar soluções criativas. Em todos os níveis de ensino, especialmente na educação superior, é preciso pensar a formação de jovens com autonomia intelectual, com paixão pela busca do conhecimento, com postura ética que os tornem envolvidos e comprometidos com os destinos da sociedade. É preciso superar o ensino centrado em caminhos já conhecidos, mas ousar e ter coragem também de ir ao desconhecido, de buscar a construção e criação de novos caminhos. Nesta perspectiva, faz-se necessário alicerçar proposições metodológicas que venham a atender às exigências de uma sociedade do conhecimento.

\subsection{Os contratos didáticos}

Considerando a necessidade de buscar outras alternativas para uma prática pedagógica que ofereça ações educativas que levem a superar a reprodução e que instiguem a produção do conhecimento, tomou-se como referência a proposta do professor ARTHUR COMBS, que adotou o modelo de Contrato de Estudo. Modelo este que foi aceito por Rogers (1971), porém na época, como recurso pedagógico, viável apenas para situações em que não é possível uma inteira liberdade de aprender. No Brasil, esse modelo foi testado por PIMENTA (1978) e relatado como superior aos procedimentos tradicionais de aula expositiva (FARIAS, 1987, p.43). O contrato de estudo, inicialmente, apresentado pelo professor COMBS, aparece com ênfase na última década, denominado como contrato didático por PERRENOUD (1999), entre outros. A nova proposição do contrato caracteriza-se por uma abordagem pedagógica crítica e reflexiva aliada a processos de avaliação formativa, integrando-se quase que "naturalmente" à gestão de situações-problema advindas da realidade.

O Contrato Didático é uma técnica estruturada e organizada das ativi- 
dades do aluno, na qual o professor entra em acordo com os mesmos sobre os conteúdos a serem estudados, o método de trabalho a ser realizado e a proposta transparente do processo de avaliação. Esse procedimento metodológico implica considerar os princípios não diretivos que podem causar impacto em certos contextos educacionais autoritários, levando muitos educadores a repensarem as relações entre mestre e aluno, colocando questões como: "necessidade de uma maior autonomia, confiança e respeito às idéias, às ações dos alunos e suas iniciativas.; relação de dominância do professor sobre o aluno" (FARIA, 1987). Daí, a necessidade, cada vez mais freqüente, de abrir espaço para o aluno como construtor de sua própria história e do seu projeto pessoal.

Para aprender jamais é supérfluo compreender o sentido daquilo que se aprende. Para tanto, o ensino deve ser centrado em conhecimentos ou em situações problema. Em uma pedagogia centrada na aprendizagem e na produção do conhecimento, o contrato didático com os alunos contempla situações de envolvimento e participação efetiva. A metodologia de aprendizagem por projetos inclui situações-problema, como propõe PERRENOUD (2000), na qual reforça o papel do aluno em participar de um esforço coletivo para elaborar um projeto e construir novas competências. Ele tem direito a ensaios e erros e é convidado a expor suas dúvidas, a explicitar seus raciocínios, a tomar consciência de suas maneiras de aprender, de organizar o conhecimento e de comunicar-se. Pede-se a ele que, de alguma maneira, em seu ofício de aluno, torne-se um prático reflexivo.( SCHON, 1994, 1996). Esse tipo de contrato didático exige um processo contínuo de aprendizagem, levando a uma maior coerência e continuidade de uma aula para a outra, e também um esforço constante de explicitação e de ajustes das regras do jogo. Na realidade, exige uma ruptura com a competição e com o individualismo.

Cabe ao professor saber e querer envolver os alunos na avaliação de suas competências, explicitando e debatendo os objetivos e os critérios, favorecendo a avaliação mútua, os balanços de conhecimento e a auto-avaliação.

As competências são construídas somente no confronto com verdadeiros obstáculos, em um processo de projeto ou resolução de problemas. E o contrato didático vem auxiliar nessa construção, uma vez que ele oportuniza aos alunos reais condições de aprendizagem.

\subsection{Elaboração dos contratos didáticos}

Os contratos didáticos (PERRENOUD, 1999) ou contratos de trabalho didático, ou plano de trabalho ou plano de organização didática, têm como objetivo desdobrar os programas de aprendizagem em encontros semanais para descrição da proposta metodológica a ser desenvolvida, bem como a indicação de bibliografia a ser investigada. 
Esse procedimento permite a visão do todo que será oferecida pelo programa de aprendizagem no semestre. $\mathrm{O}$ aluno deverá ter acesso aos programas e contratos com o intuito de saber quais aptidões, habilidades e competências serão propostas e os temas que estarão envolvidos em cada projeto.

Cabe salientar que a primeira organização fica um pouco trabalhosa, mas no decorrer do processo, vale a pena a proposição clara aos alunos sobre o que será ministrado, o que será exigido dele e o que o discente pode exigir do professor. $\mathrm{O}$ docente tem plena liberdade de elaborar o contrato didático como achar pertinente e qualificado para seu programa de aprendizagem. $\mathrm{O}$ professor precisa programar seu contrato didático para discuti-lo e dar ciência aos alunos. Nesse processo, é importante aceitar sugestões de melhoramento e contribuições significativas dos alunos, especialmente por entender que 0 interessado em aprender a aprender é o aluno, e o papel do docente é o de articular o saber elaborado à produção do conhecimento do aluno.

Nos contratos didáticos, as avaliações devem ser propostas de maneira gradual, processual e podem incluir exercícios, pesquisas, elaboração individual e coletiva de textos, resolução de problemas, montagem de relatórios, além de outros recursos que o professor julgar pertinente. $\mathrm{O}$ docente pode também optar por realizar prova, mas recomenda-se que não seja este o único instrumento avaliativo utilizado durante o semestre. $\mathrm{O}$ acesso a todos os instrumentos de avaliação corrigidos e aos critérios de correção é um direito do aluno e dever do professor. Ressalta-se que o foco é a aprendizagem do aluno e não simplesmente atribuição de notas.

Recomenda-se que nesse processo de transição o professor faça a previsão das leituras, da metodologia, das atividades que serão motivo de avaliação no processo. Neste processo, sem dúvida, é importante o diálogo entre os professores que trabalham no mesmo período ou ano letivo, pois poderão programar trabalhos ou atividades em conjunto.

Alerta-se aos docentes para buscarem caminhos de superação das pesquisas (trabalho escolar) feitos sem direcionamento, sem a organização de itens a serem pesquisados, sem problematização claramente constituída. Os docentes sabem o resultado de pesquisas extensas e fotocopiadas. Para evitar tal procedimento, é necessário buscar pesquisas mais aprofundadas, realizadas a partir de problematizações, com indicadores de possíveis caminhos para orientar a elaboração própria do aluno com qualidade e relevância.

Os alunos não podem mudar de uma atitude passiva para uma participação efetiva de uma hora para outra. É necessário, para isso, criar condições de mediar o processo de aprendizagem permitindo que o aluno prossiga com autonomia. $\mathrm{O}$ objetivo do contrato didático é instrumentalizar os alunos para desenvolverem aptidões, habilidades e competências para atuar como profissionais qualificados.

Todos os critérios e orientações, na medida do possível, devem fazer 
parte do contrato didático, pois, assim, o professor fica respaldado e o aluno sabe o que será exigido dele no processo de aprendizagem. Observa-se que a partir do momento em que o professor elabora seu programa de aprendizagem e depois o desdobra num contrato didático, a freqüência, o envolvimento e a aprendizagem dos alunos são mais efetivos.

As aulas expositivas não devem e não podem ser completamente eliminadas, no entanto, esta não deve ser a única opção metodológica a ser proposta aos alunos. O professor elabora suas argumentações e o aluno fica como ouvinte passivo neste processo. Portanto, sugere-se que os alunos se envolvam em outras atividades didáticas que requeiram mais empenho e participação deles.

As exigências de uma economia globalizada afetam diretamente a formação dos profissionais em todas as áreas do conhecimento (BEHRENS, 2000). Portanto, torna-se relevante alertar que o profissional que está sendo esperado para atuar na sociedade contemporânea deve ter uma formação com qualidade diferente da que vem sendo ofertada a um número significativo de universitários.

Numa formação compatível com as necessidades do momento histórico em que se vive, quando a produção do saber nas áreas do conhecimento demanda ações que levem o professor e o aluno a buscar em processo de investigação e pesquisa, ressalta-se a importância, dentre outros caminhos metodológicos, do estabelecimento de um projeto pedagógico que contemple programas de aprendizagem, um novo contrato didático que venha a auxiliar o aluno no processo do "aprender a aprender", no aprender a conhecer, aprender a fazer, aprender a ser e aprender a conviver, levando o aluno à construção de saberes para se tornar profissional e cidadão responsável, atuando na transformação da sociedade com uma postura ética e fraterna.

\section{Notas Bibliográficas}

1 Mestre em Educação e Doutoranda em Ciências da Educação. Professora de Didática e Prática de Ensino da PUCPR.

2 Mestre e Doutora em Educação. Professora de Didática na Pedagogia e de Paradigmas Contemporâneos no Mestrado em Educação da PUCPR.

3 RAMOS,N.; PINTO,S.; BEHRENS, M.;Botomé,S.. Diretrizes para o Ensino de Graduação da PUCPR, 2000, p.71.

4 RAMOS,N.; PINTO,S.; BEHRENS, M.;Botomé,S. Diretrizes para o Ensino de Graduação da PUCPR, 2000, p.71. 


\section{Referências Bibliográficas}

ALCÂNTARA, P. e BEHRENS, M. Pacto: Aprendizagem colaborativa com tecnologia interativa. Curitiba: PUCPR: CDROM, 2001.

BEHRENS, Marilda Aparecida. Formação Continuada e a Prática Pedagógica. Curitiba: Champagnat, 1996.

BEHRENS, M. Formação Pedagógica e os desafios do mundo moderno. In: Masetto, Marcos. (Org.) Docência na Universidade. Campinas, SP: Papirus, 1998.

BEHRENS, M.A. A prática pedagógica e o paradigma emergente. Curitiba: Champagnat, 2. ed, 2000.

BEHRENS, M. Projetos de aprendizagem colaborativa num paradigma emergente. IN: BEHRENS, M; MORAN, J. M; MASETTO, M. Novas tecnologias e mediação pedagógica. Campinas: Papirus, 2000.

CORREIA, P; MADUREIRA,C; DOMINGUES, A. Estudar problemas. In: LEITE, MALPIQUE, SANTOS. Trabalho de projecto. Leitura comentada. Porto: Edições Afrontamento, 1993.

DELORS, J.e outros. Educação: Um tesouro a descobrir- relatório para UNESCO da Comissão Internacional sobre Educação para o século XXI. São Paulo: Cortez/UNESCO, 1998.

DEWEY, J. O sentido do projecto. IN: LEITE, MALPIQUE, SANTOS. Trabalho de projecto. Leitura comentada. Porto: Edições Afrontamento, 1993.

FARIA, W. Teorias de Ensino e Planejamento Pedagógico. São Paulo: EPU, 1987.

FREIRE, P. Pedagogia da Autonomia. Saberes necessários à prática educativa. Rio de Janeiro: Paz e Terra, 1997.

GIROUX, H. Os professores como intelectuais. Rumo a uma pedagogia crítica da aprendizagem. Porto Alegre: Artes Médicas, 1997.

HERNÁNDEZ, F. A organização do Currículo por projetos de trabalho. 5. ed- Porto Alegre: Artes Médicas, 1998.

HERNÁNDEZ. F. Cultura visual, mudança educativa e projeto de trabalho. Porto Alegre: Artes Médicas, 2000. 
MORAN, J. M; MASETTO, M.T; BEHRENS, M. As novas tecnologias e mediação pedagógica. Campinas, SP: Papirus, 2000.

RAMOS, N; PINTO, S.; BEHRENS, M; BOTOMÉ, S. Diretrizes para o ensino de graduação da PUCPR. Pontifícia Universidade Católica do Paraná. Curitiba: Champagnat, 2000.

PERRENOUD, P. Dez Novas Competências para Ensinar. Porto Alegre: Artes Médicas Sul, 2000.

PERRENOUD, P. Construir as Competências Desde a Escola. Porto Alegre: Artes Médicas Sul, 1999.

Médicas Sul, 2000.

. Pedagogia Diferenciada Das Intenções à ação. Porto Alegre: Arte SCHÖN, D. Educando o profissional Reflexivo. Um novo design para o ensino e a aprendizagem. Porto Alegre: Artes Médicas Sul, 2000.

VEIGA, I.A. \& CASTANHO, M. E. (org). Pedagogia Universitária: A aula em foco. Campinas, SP: Papirus, 2000. 